\title{
Editorial: Can brand leadership recover local trust and global responsibility?
}

This editorial has been written by Chris Macrae, Ian Ryder, Jack Yan, John Caswell and Tim Kitchin, Thomas Power and Malcolm McQuarrie, and Simon Anholt. A full listing of all the contributors to this special issue concludes this editorial.

\section{CHRIS MACRAE WRITES:}

Before the customary thanks and contextualisation expected from a special editor, I wanted to be upfront about a personal belief. As I see it, we have all forgotten many of the most humanly valuable connections of brand leadership, from the core purpose of storytelling to the ways communities exchange valuable relationships and self-identities.

The greatest brand stories ever told heroise the unsung hero, sustaining a communal change of culture sufficiently for the hero to be valued. This communications process develops the community through the mutuality of producing behaviour and relationships we culturally seek to value. In my 1996 book, 'Brand Chartering,, ${ }^{1}$ I observed how brands as diverse as Coca-Cola, Lux and Budweiser have, at times in their lives, used great stories to help build national cultures and even transnational transfers of human ideals:

- Budweiser heroised blue-collar workers who build the land of the free
- Coca-Cola provided both good cheer, and the pause that refreshes at times of extreme exertion, depicted through the American GI in the Second World War, and previously the Coca-Cola factoryworkers' break in depression-ridden America

- Lux (Asia) provides women with self-confidence particularly in cultures where women seem to have less than equality.

Great storytelling is not enough, however. To serve the promise of brand leadership, people need empowering through organisational transparency so that they can see the system change they and their communities want, and in particular they need help in facilitating connections to others who will join in making this happen. A modern term for this, promoted by the European Union's Knowledge Angel movement (http://www.knowledgeboard.com/ community/zones/sig/angels.html), is 'networking of trust-flows'. At the time of writing, leaders at the World Economic Forum of 2003 are ruing how far the world's biggest organisations - both global companies and governments - have lost this human touch, as evidenced by specially commissioned surveys around the world. Mathematically we can deduce that the accountant's measurement monopoly has got performance and 
valuation measurements of intangibles' productivity wrong. Irresponsibility begins when leaders and their whole organisations are blinded to relationship risks and conflict dynamics, as illustrated by Andersen as a poster-child of value destruction. Such blindness is currently governed into the decisions and behaviour of all our world's largest organisations by classical auditing's lack of appreciation of the compound impacts of relationship dynamics. In a global world, the idea that you can separate the past from the future belongs in the realm of King Canute.

Perhaps the global human truths we most urgently need to restore begin with this idea - marketing does economics through social capitals of local communities - and not vice versa, however much administrators may love to master people. Certainly, this idea fits the change visions which Dr. Peter Drucker structures in all of his advice about how knowledge workers need to be governed by almost the very opposite of the tangible age's time-and-motion metrics if they are to contribute their greatest differences to the dynamic innovation systems central to the networked organisation. ${ }^{2}$ For sure, brands have sometimes performed the most wonderful of social engagements by providing, first, the stage/media for the social conversations that condition behaviour and progress quality of life, and, secondly, the economic revenues through corporate products to keep the people exchange well oiled with financial and other capital flows.

To restore all our lost memories of brand leadership, we need to explore total brand corporate responsibility (TBCR) with serious curiosity. We need to challenge the global brand that budgets a billion dollars annually on advertising imagery as a sham on humanity unless it connects all the way through to enabling local community progress, especially where humans are in the most desperate need. ${ }^{3}$ There is an immense amount of work to do. To start, let us simply try to revise what TBCR could mean. This is the purpose of this special issue. If our contributors create a nagging zeal in your mind that something is not right with the typical global corporation and its brand policy, their work will have been done well enough. Next, why not join up? The conversation is continuing on The Million People Web (http://www.valuetrue.com/ home/ glossary.cfm?letter=A) and I would be delighted to network you to the hottest benchmarking contacts I know of at any particular time (see contact details at end of Editorial).

My thanks to the Publishing Editor of The Journal of Brand Management, Brenda Rouse, and a special editorial team comprising those who wrote the papers, those who joined in this editorial, and three people who helped source regional contributions: Jack Yan (Southern and Eastern hemispheres), Tim Kitchin (Europe) and Dannielle Blumenthal (North America; Dannielle was director in 2002 of the Institute of Brand Leadership based in Washington, DC). Thanks also to members of the Chief Brand Officer Association, who openly share living the brand models that are media-neutral, and whose camaraderie and manifestos ${ }^{4}$ embolden my spirit. In spite of such wonderful team support, any bias in brand passion should be regarded as mine. 
Also special thanks to Simon Anholt. His special issue last year on nation branding was a huge leap forward in the contextualisation of branding, and so we are notably privileged that he has added a contribution to this editorial. His new book 'Brand New Justice - The Upside of Global Branding ${ }^{5}$ goes to the soul of the intangibles policies and communitybuilding fabrics which least-developing countries need to be granted. See review on page 380 .

The research and writing of papers for this special issue on TBCR were done in 2002. This was a year of great change among the opinion leaders in social responsibility who were revolted to find that Enron figured near the top of many corporate social responsibility (CSR) league tables until almost its last breath. Heroines of the CSR movement such as Marjorie Kelly - founding editor of Business Ethics, a 15-year-old journal — have concluded that CSR was fluff, not systemic to the way in which organisations behave and leaders make decisions. She has started a CSR 2.0 called the Economic Democracy Project (http://www.business-ethics. $\mathrm{com} /$ thenext.htm).

Brand opinion leaders have not moved so fast, nor may they do so. In large part, the call for an unstoppable momentum for change in brand leadership is up to you and this Journal. If we do not urgently vote for this, who will? It therefore seems right that this special issue comprises a curate's egg of papers reflecting both views of how brand and CSR practices are still being done, and calls for systemic change.

This editorial has a particular role to play. It is the combined work of various people who are committed to networking varied areas of future expertise and who were brave enough to take up the invitation to make a one-page contribution on what they would like to say about, or what they hope for, our future responsibilities with branding. In some cases they also introduce us to new constructs that could influence the design of truly new media in order to responsibly support our coming of age in mankind's networking century.

I have worked on global brands in 30 countries, for over 25 years, including a long period before branding became an academic discipline. In my observational experience, global and corporate branding was performed better 25 years ago when it often still integrated founder's values, perhaps because specialists had not started working on the executional parts of what should be the DNA of the system of beliefs that a company cares about. In those days, companies earned local relationship respect as part of becoming global. We need to rediscover that deep worldwide sense of responsibility. Relationship reciprocity is, after all, the one golden rule uniting all the world's major religions, and brands can be modelled to the way a company values the system dynamics of its relationship capital.

If a Martian came down to earth and spotted that the world's most powerful organisations communicate their impact through superficial 30second image sound bites called television spots - spending up to US $\$ 1 \mathrm{bn}$ a year on such image narcissism I believe that Martian would conclude that this was a diseased planet whose civilisations were not going to pass what systems theorist Buck- 
minster Fuller ${ }^{6}$ foresaw 20 years ago as mankind's coming final examination, posed by the new technology's connectivity, which puts all of our relationships and behaviour in each other's laps. The oft-claimed statement that we do not have many proven models of branding other than advertising-centric ones is false, for two reasons. First, marketing and branding people are supposed to be:

- The innovators of value and productivity.

- The sustainability experts of a company's unique leadership platform and social fabric.

- Those who provide a healthy system tension to everyone of a shorter bent. Read the 1950 lips of organisational expert Peter Drucker in the 'Practice of Management $^{\text {'7 }}$ if you need to assure yourself.

Secondly, if you look back before 1980 you will see that most of the great global brand models were, in origination, responsibility-led. It is just we did not have the meta-disciplinary language to codify them. After 1980 a series of management accidents overwhelmed our common senses. Intangibles productivity was suddenly recognised to be the paramount success driver. Accountants preferred to perpetrate their measurement monopoly of management in parts (with selfdefined algorithms like brand valuation) of the very system dynamics that needed to be deeply humanly connected, openly co-responsible and networked worldwide. Then the personal computer came along and, with its first killer application of the spreadsheet it diffused 'Herculean micromanage- ment'. ${ }^{8}$ This incorrect approach to intangibles' productivity is the root cause of why Andersen lost its vision, why the World Economic Forum theme of 2003 is '(lost) trust', and that of 2002 was 'leadership as the process of earning greater integrity of relationships with all stakeholders'. That is just a sample of lost business cases; the lost social cohesion is what stops me from sleeping at night when I think about my 5-year-old daughter's future world.

The good thing about freedom of speech is that if you feel uncomfortable with my view you can read another and another. I will end my editorial contribution with the words of my father - who was deputy editor of The Economist, the first global 'viewspaper', over four decades - penned in 1984 in a book celebrating the passing of Orwell's 'big brother', and chronicling how the networking age would evolve up to $2024:^{9}$

'By 2005 the gap in income and expectations between the rich and poor nations was recognised to be man's most dangerous problem. Internet linked television channels in sixty-eight countries invited their viewers to participate in a computerised conference about it ...?

Come to think of it that would be a truly global co-branding responsibility platform to sponsor — the 'brandaid' of this decade - why not just do it?

Chris Macrae Special Issue Editor Journal of Brand Management January 2003

\section{IAN RYDER WRITES:}

Coca-Cola recently stated it will no 
longer provide Wall Street with quarterly performance estimates. Could this be the start of a trend away from the much-disliked (by businesses) shorttermism that has caused many management problems, not least the lack of any true embracing of strategic corporate responsibility, because it is not easily and readily tuned into the hard, unimaginative ratios so loved and rewarded by analysts? This little ray of light has turned my own thinking from a point where I did not believe that TBCR would make any real progress in the next three to five years, to a view that CSR-inspired behaviour may actually become an established systemic component of brand (reputation) management.

Most public companies, driven by the demands of the analysts, suffer the same institutional myopia of longerterm strategic behaviour that causes many to under-invest in their brand management. Most non-public companies, government organisations and even countries similarly have little understanding of strategy, and, in all of these, discussions about 'responsibility' mean different things. Rowan Wilson, the editorial director of Strategic Communications Management magazine, recently wrote a very good paper on reputation management, ${ }^{10}$ in which she quoted some seriously pointed research facts:

- last year a poll of 25,000 citizens across 23 countries on six continents showed that perceptions of companies around the world are shaped more by corporate citizenship (56 per cent) than either brand quality (40 per cent) or business fundamentals (34 per cent)

- 81 per cent of consumers agree that when price and quality are equal they are more likely to buy a product associated with a cause - 73 per cent agree that they would be more loyal to an employer that supports the local community.

TBCR, then, is not just about ecology and it is not just confined to a single geography. It is a broad-based, global issue that all businesses that wish to survive and prosper in the longer term must understand and embrace. 'Responsibility' is going to require that real change in organisations, not just 'lip-service', occurs within a reasonable timeframe. Will this be three to five years? Only time will truly tell, and the fact that strategic programmes are not helped by CEO tenure being down to around two years (on average) will also play a part. We know brands are about trust, which is earned, and not a right, and we have to drive this TBCR understanding, through the trust and transparency debate, into the boardroom. The 'responsibility' dimensions used in the brand management practices of my own company are probably the same as yours: environment, employees, ethical trading and community. Am I able to say that this currently has a large role in the strategic operations and decisionmaking of the business? Actually no - not yet. Is the focus and importance growing within the business? Absolutely, which is where I have hope.

A shift in the short-term behaviour of business, if the Coca-Cola position is repeated by others, as I hope, added to the growing pressures of customer, community and, let's face it, global (human) needs, could well see TBCR 
established as a fundamental of brand (reputation) management — business management - within the next three to five years. We just need to ensure that we also build integrated measures that are equally embedded within the strategic and operational systems of organisations - in fact, should this not come first?

\section{Ian Ryder Editorial Board Journal of Brand Management January 2003}

\section{JACK YAN WRITES:}

The best ideas have a funny way of shifting from the fringe to the mainstream. ${ }^{11}$ Last year, many of the warnings that business commentators had given - the overvalued stock on Wall Street, the absence of proper ethics, the wrongful methods by which organisations are valued appeared to have been heeded, as President Bush announced his government's programme in light of the Enron debacle. ${ }^{12}$ The December 2002 appointment of John W. Snow, who apparently is on the same page as President Bush on corporate responsibility, as Secretary of the Treasury, is arguably another sign. Despite this - perhaps seen as tokenism by some - CSR has not become an unavoidable part of the business landscape, largely because organisations see no shareholder gain by following that route. It is a cost, just like paying employees, that harms shareholder return. As information becomes more accessible, consumers more discerning and the gap between rich and poor widens (even if overall wealth has increased), however, the hopeful view is that the next decade will see a realisation that something is rotten in Denmark, and it is not just right-wing politicians wanting to kick Turks out.

In a decade, we might look back on 2002 as just another year in an evolution that began with the founding of Business Ethics in 1987. Its editor, Marjorie Kelly, once espoused the view that corporations were becoming more humane and would change voluntarily, but now believes there is something wrong with the way in which we hold dear a system so obsessed with shareholder gain at the expense of what might be termed 'corporate humanity'. ${ }^{13}$

Meanwhile, I put forward a view that might have spawned from the same nucleus as Kelly's original thoughts: that branding, the primary interface between corporation and public, will become more honest because consumers, or even potential employees, demand that, viz Bill Ford's comment in Garten. ${ }^{14}$ While there are signs that this is right in some instances, ${ }^{15}$ particularly with founderrun companies - and I remain confident when it comes to the demands of today's Generation Y consumers in one paper in this issue there is an immovable clutter of old-style businesses that will not follow suit, because the system, as it stands, will not allow it. There is, however, one way to impress what will become the world's most influential consumer group: by being transparent and socially responsible.

While there are regions where CSR will not get a head start, such as the United Arab Emirates (interview by the author with United-Arab- 
Emirates-based brand expert Alison Meldrum, November 2002), networks are forming. Books are being written, such as Kelly's 'The Divine Right of Capital', ${ }^{16}$ while this profession knows of 'No Logo' and various works about globalisation. Jeffrey Garten at Yale encourages corporate citizenship. ${ }^{17}$ Columnist and author George Monbiot is about to release a book that is pro-globalisation, but a form that is democratised, recognising a fragmented world and a need for 'interlinked global justice'. ${ }^{18}$

These nudges seem to indicate a middle route, where CSR's influence will evolve. In a world where branding is polycentric and populations are heterogeneous, where the occident is roughly united in its desire for ethical business practices, CSR may at first be practised in a half-hearted fashion, because it is seen as mere fashion. A moderate version of it may then be internalised so as not to conflict with the status quo. Going full steam ahead risks creating too much opposition (or encountering odd bedfellows) in this fragmented world; ignoring it goes against President Bush's recent call, the 'executives in handcuffs' parade and the 'army' of consumer opinion.

Once CSR is inside, as the increase in the number of marketers on boards of directors has shown us, there are gradual power shifts. Corporate boards are less ignorant of marketing whereas once they were mainly interested in finance. Almost out of necessity, CSR becomes strategic - beginning perhaps as part of marketing and public relations, and ending up as accepted 'Management 101' fare. While CSR may enter the organisation via branding, because it must appeal to consumers who demand it as part of a brand mix, and because it is a means for differentiation, branding's role may alter to become a tool of a top-driven CSR drive in the medium term.

CSR itself might not change in concept, nor will its core model vary. The student or practitioner of 2012 will read this Journal and note the similarities in CSR's ideas and their relationship to branding. Ideally, we hope that we have, in the next decade, done enough for that student to view our world, where CSR is not yet a regular part of brand management, to be a quaint place.

\section{Jack Yan \\ Founder of Jack Yan \& Associates, the parent company of JY \& A Consulting December 2002}

\section{JOHN CASWELL AND TIM KITCHIN WRITE:}

You are what you edit. The following is an exhortation to embrace positive context:

"World is crazier and more of it than we think,

Incorrigibly plural. I peel and portion A tangerine and spit the pips and feel The drunkenness of things being various.' Extracted from 'Snow', Louis MacNiece ${ }^{19}$

Most of us would agree that complexity has reached a tipping point. Or rather, our awareness of complexity has reached a tipping point. Or rather, our susceptibility to complexity has reached a tipping point. Whichever it is - the ability of individuals, of 
organisations, and of nations to hold fast to a steady course gets weaker day by day.

In the past half century, the way the world works has changed in fundamental ways: linear processes, hierarchical power structures, predictable stakeholders, clear modes of differentiation ... have all evaporated, irrevocably. But more importantly still, the way we interpret the world has begun to mutate under an avalanche of subjective media. The supremacy of purely rational thought-processes is being challenged by the emotional, the subjective, the cultural. Multiply this by the great value paradoxes which are emerging from being intimately connected by technology: global and local, real and virtual, responsible economically and socially ....

At a loss to assimilate content fast enough to make big-picture decisions, we turn to analyse smaller and smaller pieces of the jigsaw in a desperate bid to maintain a pretense of certainty. But there may yet be another way: to embrace complexity. Let the content look after itself. Seek context. Most importantly, seek to establish 'positive context' and share that context as fast, as openly and as widely as possible. Positive context builds trust, which inspires confident action and trusting response ... and so shapes sustainable markets. The total corporate responsibility referred to in the title of this special issue is not just a responsibility to act with honour and consistency, as a corporate citizen, but to acknowledge a responsibility as a shaper of economic, market and social context.

Dramatic increases in performance, and sustainable competitive advantage do not come from the slow evolution of conventional business processes, most of which remain constant over long periods of time. They come instead from wholesale reinventions or value innovations - enabled by the creation of an entirely fresh mental context, which ignores the surface form of an organisation or a market and seeks to understand the underlying dynamic structure instead - its reconfigurable substance, composed of stakeholders' wants and aspirations and organisations' ability to meet them.

\section{But what is positive context?}

Positive context is a rich and purposeful framework which guides organisational decision-making at all levels. It is not simply a personal mental model, it is a shared and directed understanding created within and around an organisation - by the organisation's own stakeholders as participants. When truly embraced, positive context does not stay within the organisation - it migrates beyond the organisation as a sense of common cause and shared benefit among stakeholders. Part vision, part mission, part cause - positive context embeds itself in the socio-economic fabric. It drives strategic innovations in stakeholder experiences, and innovations in stakeholder relationships, brought to life through re-imagined interactive processes and mutual learning experiences.

'Totally responsible' businesses, in this sense, are those that are not only brand-true and market-true, but socially-true. They are authentic to their brand cause. These are the context kings. 'True' businesses like Virgin, Body Shop or South-West Airlines did 
not simply re-engineer their content, they created positive context.

\section{John Caswell and Tim Kitchin Co-founder of Group Partners and Founder of The Brand-Learning Company, respectively January 2003}

\section{THOMAS POWER AND MALCOLM MCQUARRIE WRITE:}

'Routecause" ${ }^{20}$ is a book and a research programme examining the hypothesis that a brand and a cause will become one. We are drawing on the experiences of our peer community at www.ecademy.com - currently over 13,000 professionals concerned with networking practice. Briefly, here are some of the key perspectives that are shaping our hypothesis:

- Global deterioration: Global deteroration will become the number one issue facing our lives. This view is open to argument, but many projections concur that things will get much worse before they get better. As more and more people are drawn into the struggle to survive and maintain a reasonable quality of life, brands will find it impossible to differentiate themselves on the basis of vacuous lifestyle statements. They must become solutions to economic, social and environmental problems, or causes.

- A networked world: Networking is one of the oldest forms of human practice, it is also one of the most powerful. In the last century, broadcasting largely overshadowed networking. In this century, networking technologies are enabling new and more powerful networks of people to emerge. What binds these networks together are common interests and concerns such as causes. Brands can no longer lean so heavily upon broadcasting and advertising to communicate. They must engage in conversations with the new networks as well. To do so they need to adopt their causes with total conviction.

- CSR: Sceptics may argue that brands that adopt the principles of CSR are only paying lip service. Often this is true, but many are discovering that CSR produces a real competitive advantage. In December 2002, Gordon Brown, the British Chancellor of the Exchequer, described CSR as a 'smart strategy'. ${ }^{21}$ CSR is a movement that is continually evolving. It is the beginning of a shift away from the view that brands exist only to produce financial wealth at any cost to the wider community. CSR as we know it today is just the beginning.

\section{Where do we see this leading us?}

People care about the world they live in as well as the other people and creatures that share it. They have good reason to be very concerned about the world's welfare, and are finding a powerful voice to express their concerns via the new networks. Collectively, big brands are the most wealthy and powerful institutions that exist today. Individually, many are more wealthy and powerful than most national governments. They have the resources to bring about positive change. They should use these resources responsibly and be guided by the new networks. We are spotting emerging signs that suggest this trend is 
already starting. The survival of a brand will depend upon its becoming a solution to problems and issues. The way for a brand to be sure of its future is to become a true cause.

\section{Thomas Power and Malcolm McQuarrie Founder and Chairman of Ecademy.com and freelance writer respectively January 2003}

\section{SIMON ANHOLT WRITES:}

So much talk - and so much of it praiseworthy - about how western corporations need to think more responsibly, protect the environment, respect their customers and suppliers, as well as their shareholders and directors. Why do western corporations need watching so closely? Because they are so rich and powerful, of course - as commentators have endlessly pointed out, some companies are bigger and more powerful than countries. Big western corporations - and their consumers - hold the destiny of many poorer countries in their hands.

Is it not funny, though, how nobody ever questions the underlying assumption that the big, rich and powerful corporations always have been, and always will be, from the north, and their consumers and suppliers - in Naomi Klein's book, ${ }^{22}$ their victims - from the south? Just suppose that those powerful corporations and brand-owners were distributed around the world a little more evenly. Suppose that some of the global mega-brands were actually produced by, and owned by, companies in much poorer countries. How different would our concerns be today if the companies whose products were manufactured in the sweatshops of Puerto Rico and China were actually Puerto Rican or Chinese? How would our CSR agenda look if Nike were Nigerian or Pepsi Peruvian? It may sound like a daft idea, but consider for a moment how the UK and the USA and Germany and Japan and all the other powerful brand-owning nations managed to become powerful brand-owning nations in the first place: partly because of their skill in the art and science of branding. That is where the margins are these days, and brand value may account for as much as a third of all the wealth on the planet. Brands are among the most potent of our modern tools for creating and sustaining wealth, and they almost never come from outside the hallowed circle of ten or 12 rich, brand-producing countries in the northern hemisphere.

Hence I believe that the new task and challenge for marketing in the 21st century is branding skills transfer. Real CSR is about making those immensely potent tools of wealth creation available to the countries and companies which really need to get richer. Wondering how to wield unimaginable wealth and power more sensitively is, after all, quite a nice problem to be faced with. Let us worry, by all means, about compelling today's multinationals to do so: but an altogether higher aim would be ensuring that some more deserving nations and corporations one day acquire a few of the same problems.

Simon Anholt Founder of Earthspeak January 2003 


\section{CONTACT DETAILS}

The editors, editorial contributors and paper contributors invite your continuing conversation on how to progress these matters. Here is a table of our contact details:

\begin{tabular}{lll}
\hline Name & E-mail & Web \\
\hline Chris Macrae & wcbn007@easynet.co.uk & www.valuetrue.com \\
Brenda Rouse & brenda@hspublications.co.uk & wcbn008@jyanet.com \\
Jack Yan & tim.kitchin@grouppartners.net & www.jyanet.com \\
Tim Kitchin & dblumenthal@instituteforbrandleadership.org & www.brand-learning.com \\
Dannielle Blumenthal & john@grouppartners.net & www.instituteforbrandleadership.org \\
John Caswell & ian.ryder@gb.unisys.com & www.grouppartners.net \\
lan Ryder & simon@earthspeak.com & www.unisys.com \\
Simon Anholt & thomas.power@ecademy.com & \\
Thomas Power & malcolm@mcquarrie.demon.co.uk & www.ecademy.com \\
Malcolm McQuarrie & michaelw@futurefoundation.net & www.ecademy.com \\
Michael Willmott & abela@cua.edu & www.futurefoundation.net \\
Andrew Abela & steve@goodbusiness.co.uk & \\
Steve Hilton & ron.irwin@iafrica.com & www.goodbusiness.co.uk \\
Ron Irwin & nigelm@echoresearch.com & \\
Nigel Middlemiss & a.brady@jims.cam.ac.uk & www.echoresearch.com \\
Arlo Brady & & \\
\hline
\end{tabular}

\section{References}

(1) Macrae, C. (1996) Brand Chartering - How Brand Organisations Learn 'Living Scripts', Addison Wesley.

(2) Drucker, P. F. (1999) 'Knowledge-Worker Productivity: The Biggest Challenge', California Management Review, Vol. 41, No. 2, Winter, pp. 79-94; Drucker, P. F. (2002) Management Challenges for the 21st Century, Harper Business, USA.

(3) Gordon, W., Macrae, C. and Mitchell, (2003) The Map, Wiley.

(4) Yan, J. (2003) 'The brand manifesto', http://www.allaboutbranding.com/ index.lasso? article $=278$.

(5) Anholt, S. (2003) 'Brand New Justice - The Upside of Global Branding', Butterworth Heinemann.

(6) BBC Reith Lectures (2002), www.bbc.co.uk/radio4/reith2002.

(7) Drucker, P. (1995) Practice of Management, Heinemann.

(8) BBC Reith Lectures ref. 6 above.

(9) The Norman Macrae Archive, 'Future history', http://www.normanmacrae.com/ netfuture.html

(10) Wilson, R. (2003) 'Keeping a watch on corporate reputation', Strategic Communications Management (SCM), Vol. 7, Issue 2, Dec/Jan.

(11) Matthews, R. and Wackwer, W. The Deviant's Advantage: How Fringe Ideas Create Mass Markets, Crown Business, New York, NY, USA.
(12) Walczak, L., Dunham, R., Dwyer, P., Cohn, L., Zellner, W., Smith G. and Scotti, C. (2002) 'Let the reforms begin', Business Week, 22nd July, pp. 36-41.

(13) Kelly, M. (2001) The Divine Right of Capital: Dethroning the Corporate Aristocracy, Berrett-Koehler Publishers, San Francisco, CA, USA. p. xii.

(14) Garten, J. (2002) 'Globalization without tears: A social compact for CEOs', Strategy $\mathcal{E}$ Business, Fourth Quarter, pp. 36-45.

(15) Byrne, J. (2002) 'After Enron: The ideal corporate', Business Week, 26th August, pp. 40-43.

(16) Kelly, ref. 13 above.

(17) Garten, J., ref. 14 above; Garten, J. (2002) The Politics of Fortune: A New Agenda for Business Leaders, Harvard Business School Press, Harvard, USA.

(18) Monbiot, G. (2003) The Age of Consent, in Hari, J.: 'Whatever happened to No Logo?', New Statesman, 11 November (2002), pp. 20-22.

(19) MacNiece, L. (1966) The Collected Poems of Louis MacNiece, Faber \& Faber.

(20) Powers, T. and McQuarrie, M., (2003) Routecause, Ecademy.

(21) AGM of Business in the Community on 5 December, 2002, http:/www.2.bitc.org.uk/events/event_proceedings/agm_2002/brown_speech.html

(22) Klein, N. (2002) Fences and Windows: Dispatches from the Frontlines of the Globalization Debate, Flamingo. 